\title{
Neurocritical Care in Eastern Nepal: Challanges and
}

\section{Opportunities}

\author{
Niraj Kumar Keyal ${ }^{1}$ \\ ${ }^{1}$ Department of Critical Care Medicine, B \& C Medical College and Teaching Hospital \\ \& Research Center,Birtamode,Jhapa,Nepal

\section{Correspondence:} \\ Dr Niraj Kumar keyal. \\ Department of Critical Care Medicine, B \& C Medical College and Teaching Hospital \& \\ Research Center,Birtamode,Jhapa,Nepal. \\ Email: nirajkumarkeyal@gmail.com \\ Phone: +9779855027141
}

Sir,

$\mathrm{N}$ epal is a developing country lacking health care facilities. Most of developing countries including Nepal has lack of health services that has led to high morbidity and mortality.

Critical care medicine has been recognized as a superpeciality in most of the developed countries and in some developing countries. ${ }^{[1]}$ There is only 15.2 intensive care unit (ICU) beds per 100,000 and 7.2 ICU beds with ventilator. Most of ICU are open run by anaesthesiologist, internist and surgeons. Most of ICU that provides high level of care is concentrated at Kathmandu. There is a lack of well equipped ICU, intensivist, nurses outside Kathmandu valley therefore, patients are referred to Kathmandu and India for critical care management that add cost to patient and increases the mortality and morbidity of patients. There are only few intensivist in Nepal who has done their training in critical care and practicing critical care. B \&C Medical College at Birtamode is only hospital outside the kathmandy valley that is 34

Date Submitted: 22/8/2019

Date Accepted: 11/9/2019 providing critical care services by intensivist who has done three years formal training in critical care medicine. This has lead to decrease in mortalily,morbidity and increase the quality of care to patient of eastern part of Nepal.

Neurocritical care provides critical care services to neurological patients.Neurosurgery and Neuromedicine services are provided only few hospitals in eastern Nepal at Biratnagar and Birtamode. There is lack of neurological services in most of hospitals. Studies have shown that trauma is most common reason for seeking neurological services. ${ }^{[2]}$ There is a lack of trained critical care physician and neurointensivist in Nepal and developing country so, neurological patients are managed by neurologist, neurosurgeons, anaesthetists and internist. Studies have shown that closed ICU managed by neurointensivist and intensivist has better outcome than open ICU. $\left[{ }^{3,4,5]} \mathrm{B} \& \mathrm{C}\right.$ Medical college runs closed ICU managed by trained neurointensivist that has provided better outcome of patients.

egneuro, Volume 01, Issue 02, 2019 DOI: https://doi.org/10.3126/egn.v1i2.25734 
There has been a change in epidemiology of neurological patient. In past, infection was most common but presently non communicable diseases like trauma, aneurysm, traumatic brain injury, spinal cord injury are most common. ${ }^{[6]}$ These changes in disease pattern requires high degree of expertise of neurocritical care services. It requires electroencephalogram, intracranial pressure monitoring devices in the neurointensive care in addition to general critical care. There is a lack of instruments, manpower, funding and government attention in neurocritical care. It requires adequate training for nurses, medical officers and consultant,pre hospital training on trauma patients, research and fellowship.There is no formal training for neurocritical care in our country though neurocritical care society has started on line course for emergency neurocritical care.

To conclude Neurocritical is a superspeciality that reuies adequate attention and developemet in developing country like Nepal from all aspects and I hope we will succeed one day.

\section{References:}

1. Acharya SP. Critical Care Medicine: An Emerging superspeciality in Nepal.

JSAN 2014;1:55-8.

2. Roka YB, Ahmad SW, Shrestha M, Chaudhary A, Puri PR, Adhikari HB et $a l$. Neurosurgical intensive care. PMJN 2010;10(2):71-4.

3. The impact of open versus closed format ICU admission practices on outcome of high risk surgical patients: a cohort analysis. BMC Surg 2011;11:18.

4. Vincent JL. Evidence supports the superiority of closed ICUs for patients and families:Yes. Intensive care med 2017;43(1):122-3.

5. Chittawatanarat K, Pamorsinlapathum T. The impact of closed ICU model on mortality in general surgical intensive care unit. J Med Assoc Thai 2009;92(12): 1627-34.

6. Shrestha GS, Goffi A, Aryal D.Delivering neurocritical care in resource-challanged environments. Curr Opin Crit Care 2016;22(2):11-5. 